\title{
Ciclagem de nutrientes por plantas de cobertura e produtividade de soja e arroz em plantio direto
}

\author{
Leandro Pereira Pacheco(1), Juliano Magalhães Barbosa(2), Wilson Mozena Leandro(3), \\ Pedro Luiz Oliveira de Almeida Machado(4), Renato Lara de Assis( ${ }^{(5)}$, \\ Beáta Emoke Madari(4) e Fabiano André Petter ${ }^{(6)}$
}

\begin{abstract}
(1)Universidade Federal de Mato Grosso (UFMT), Departamento de Engenharia Agrícola e Ambiental, Campus Universitário de Rondonópolis, Rodovia Rondonópolis-Guiratinga, Km 06 (MT-270), Sagrada Família, CEP78735-910Rondonópolis, MT.E-mail: leandroppacheco@gmail.com (2)Universidade Federal de Goiás (UFG), Caixa Postal 131, CEP 74001-970 Goiânia, GO. E-mail: julianomagbarbosa@hotmail.com (3)UFG, Departamento de Solos, Rodovia Goiânia-Nova Veneza, Km 0, Campus II, CEP 74001-970 Goiânia, GO. E-mail: mozena@bol.com.br (4)Embrapa Arroz e Feijão, Caixa Postal 179, CEP 75375-000 Santo Antônio de Goiás, GO. E-mail: pedro.machado@embrapa.br, beata.madari@embrapa.br ${ }^{(5)}$ Instituto Federal Goiano, Campus Iporá, Rodovia GO 060, Km 1, Zona Rural, CEP $76200-000$ Iporá, GO. E-mail: relassis@bol.com.br (6)UFMT, Departamento de Agronomia, Campus Universitário de Sinop, Avenida Alexandre Ferronato, no 1.200 , Setor Industrial, CEP 78557-267 Sinop, MT. E-mail: fabianopetter@brturbo.com.br
\end{abstract}

Resumo - O objetivo deste trabalho foi avaliar a ciclagem de nutrientes por plantas de cobertura e a sua influência sobre o desempenho da rotação entre arroz de terras altas e soja. As culturas foram implantadas sob plantio direto, em Latossolo Vermelho distroférrico, na região do Cerrado de Goiás. As plantas de cobertura foram semeadas mecanicamente, também em plantio direto, após a colheita da soja (25/3/2008) e do arroz (7/4/2009). Utilizou-se o delineamento de blocos ao acaso, com parcelas subdivididas no tempo e quatro repetições. Os tratamentos consistiram das seguintes espécies de plantas de cobertura, além do pousio: Urochloa ruziziensis, U. brizantha, Pennisetum glaucum e U. ruziziensis + Cajanus cajan. A avaliação dos nutrientes remanescentes na palhada foi feita aos: 0, 15, 30, 60, 90 e 120 dias a partir da data da dessecação das plantas de cobertura. Urochloa ruziziensis e U. brizantha apresentaram maior eficiência no acúmulo e na liberação de nutrientes, principalmente quanto ao potássio. Urochloa ruziziensis é a espécie mais indicada como planta de cobertura antecessora à cultura do arroz de terras altas, em plantio direto. No entanto, nenhuma espécie de cobertura afeta significativamente a produtividade de grãos da soja.

Termos para indexação: Brachiaria brizantha, Brachiaria ruziziensis, Pennisetum glaucum, arroz de terras altas, rotação de culturas, sucessão de culturas.

\section{Nutrient cycling by cover crops and yield of soybean and rice in no-tillage}

\begin{abstract}
The objective of this work was to evaluate nutrient cycling by cover crops and its influence on the performance of the rotation between upland rice and soybean. The crops were sown under no-tillage, in a Rhodic Haplustox, in the Cerrado region of the state of Goiás, Brazil. The cover crops were sown mechanically, also under no-tillage, after the harvest of soybean (3/25/2008) and rice (4/7/2009). A randomized complete block design was used, split-plotted in time, with four replicates. The treatments consisted of the following cover crop species, besides fallow: Urochloa ruziziensis, U. brizantha, Pennisetum glaucum and U. ruziziensis + Cajanus cajan. The evaluation of the remaining nutrient in straw was performed at $0,15,30,60,90$, and 120 days from the desiccation date of the cover crops. Urochloa ruziziensis and U. brizantha were the most efficient in the accumulation and release of nutrients, especially potassium. Urochloa ruziziensis is the most suited species for use as a cover crop previous to upland rice cultivation under no-tillage. However, none of the cover crop species significantly affect soybean grain yield.
\end{abstract}

Index terms: Brachiaria brizantha, Brachiaria ruziziensis, Pennisetum glaucum, upland rice, crop rotation, crop succession.

\section{Introdução}

O arroz de terras altas foi a principal cultura utilizada na conversão do Cerrado para a agricultura, entre as décadas de 1970 e 1990. Com o tempo, a soja, comumente em monocultivo, passou a ocupar a maioria das áreas agrícolas nesse bioma. Como a sustentabilidade do sistema plantio direto reside na rotação de culturas e no uso de plantas de cobertura para a formação de palhada sobre o solo, o arroz de terras altas é uma alternativa ao milho, na rotação com 
a soja, principalmente para a reforma de pastagens, que cobrem a maior parte da região de Cerrado sob uso (Sano et al., 2008; Breseghello et al., 2011).

O desempenho do arroz de terras altas em sistema plantio direto, no entanto, tem sido controverso. Segundo Kluthcouski et al. (2000), o baixo vigor inicial dificulta sua inclusão na rotação de culturas. Todavia, Reis et al. (2008) constataram que apesar de o plantio direto ter reduzido a altura de planta e alongado o ciclo da cultura, a produtividade do arroz não se alterou em comparação ao plantio convencional.

Pacheco et al. (2011b) relataram que o milheto (Pennisetum glaucum), em sistema plantio direto, acumula expressiva quantidade de fitomassa e nutrientes no início da entressafra (destaque para $\mathrm{NeK}$ ). Neste estudo, as espécies Urochloa brizantha cultivar Marandu, U. ruziziensis e o consórcio U. ruziziensis + Cajanus cajan apresentaram alto potencial de acúmulo de fitomassa e nutrientes ao final da entressafra. Em outro trabalho, Pacheco et al. (2011a) observaram elevados índices de liberação de nitrogênio e fósforo após a dessecação dos cultivos de cobertura, e maiores produtividades de arroz nos tratamentos precedidos pelo cultivo de $P$. glaucum, em sistema plantio direto.

A baixa disponibilidade de $\mathrm{N}$ amoniacal pode limitar o desenvolvimento inicial do arroz em plantio direto, em razão da baixa atividade da nitrato redutase nas plântulas, o que diminuiria a assimilação do nutriente nas plantas. Assim, o uso de plantas de cobertura capazes de disponibilizar, via mineralização, maiores quantidades de amônio ao solo e de elevar o teor de matéria orgânica (Kalbitz et al., 2000) pode viabilizar a produção de arroz de terras altas, em rotação com soja, de forma sustentável. Embora o suprimento de $\mathrm{N}$ na soja esteja associado à fixação biológica, há indícios de que a cultura responde bem à sua disponibilidade no solo, nos estádios iniciais de crescimento, em decorrência da baixa eficiência dos nódulos (Reis et al., 2001).

O objetivo deste trabalho foi avaliar a ciclagem de nutrientes por plantas de cobertura e a sua influência sobre o desempenho da rotação entre arroz de terras altas e soja.

\section{Material e Métodos}

O estudo foi conduzido na Fazenda Capivara, na área experimental da Embrapa Arroz e Feijão, no Município de Santo Antônio de Goiás, GO (16²8'00"S, $49^{\circ} 17^{\prime} 00^{\prime \prime} \mathrm{W}$, a $823 \mathrm{~m}$ de altitude), de março de 2008 a abril de 2010.

O experimento foi implantado sobre Latossolo Vermelho distroférrico (Santos et al., 2006), com as seguintes características granulométricas e químicas, na camada de 0,00-0,20 m: 549, 106 e $345 \mathrm{~g} \mathrm{~kg}^{-1}$ de argila, silte e areia, respectivamente; $\mathrm{pH}$ em $\mathrm{CaCl}_{2}$ de 5,2; 6,3 $\mathrm{mg} \mathrm{kg}^{-1}$ de P (Mehlich 1); 0,2 $\mathrm{cmol}_{\mathrm{c}} \mathrm{dm}^{-3}$ de K; 2,4 $\mathrm{cmol}_{\mathrm{c}} \mathrm{dm}^{-3}$ de Ca; 0,7 $\mathrm{cmol}_{\mathrm{c}} \mathrm{dm}^{-3} \mathrm{de} \mathrm{Mg} ; 4,2 \mathrm{cmol}_{\mathrm{c}}$ $\mathrm{dm}^{-3}$ de $\mathrm{H}+\mathrm{Al} ; 24,0 \mathrm{~g} \mathrm{~kg}^{-1}$ de matéria orgânica; CTC de $7,6 \mathrm{cmol}_{\mathrm{c}} \mathrm{dm}^{-3}$; e $44 \%$ de saturação por bases.

Antes da instalação do experimento, a área havia sido cultivada com soja/pousio, em sistema plantio direto, e permanecido em pousio nas safras 2005/2006 e 2006/2007. As precipitações ocorridas durante a condução dos experimentos estão representadas na Figura 1. Na safra 2007/2008, realizou-se nova calagem e cultivou-se a soja, cultivar Emgopa 302RR, em plantio convencional, com adubação de $400 \mathrm{~kg} \mathrm{ha}^{-1}$ da fórmula 00:20:18 $\left(\mathrm{N}: \mathrm{P}_{2} \mathrm{O}_{5}: \mathrm{K}_{2} \mathrm{O}\right)$.

A colheita da soja ocorreu em 22/3/2008, com produtividade média de grãos de $3.000 \mathrm{~kg} \mathrm{ha}^{-1}$. Em 25/3/2008, realizou-se a semeadura das plantas de cobertura, em primeiro ano, em blocos ao acaso, com arranjo de parcelas subdivididas no tempo e quatro repetições. Os tratamentos consistiram de quatro espécies de plantas de cobertura e uma área em pousio: Urochloa ruziziensis (Syn. Brachiaria ruziziensis), $10 \mathrm{~kg} \mathrm{ha}^{-1}$ de sementes com valor cultural (VC) de $70 \%$; U. brizantha (Syn. B. brizantha), $10 \mathrm{~kg} \mathrm{ha}^{-1}$ (VC de 70\%); Pennisetum glaucum cultivar ADR 300, $13 \mathrm{~kg} \mathrm{ha}^{-1}$ de sementes; U. ruziziensis $+C$. cajan, $5 \mathrm{~kg} \mathrm{ha}^{-1}+10 \mathrm{~kg} \mathrm{ha}^{-1}$ de sementes, respectivamente; e pousio, vegetação espontânea, com predominância de trapoeraba (Commelina benghalensis), buva (Conyza bonariensis) e picão-preto (Bidens pilosa). As plantas de cobertura foram semeadas mecanicamente, em plantio direto, com espaçamento entre linhas de $0,25 \mathrm{~cm}$, sem uso de fertilizantes. A parcela foi de $8 \mathrm{~m}$ de largura por $16 \mathrm{~m}$ de comprimento.

No primeiro ano de estudo (safra 2008/2009), a dessecação das plantas de cobertura foi feita em 21/10/2008, com o herbicida glifosato (1.468 $\mathrm{g} \mathrm{ha}^{-1}$ e.a.) + 2,4-D (335 $\left.\mathrm{g} \mathrm{ha}^{-1}\right)$. A semeadura do arroz de terras altas foi feita em sistema plantio direto, em 28/11/2008, 36 dias após a dessecação, com espaçamento de $0,40 \mathrm{~m}$ entrelinhas e 213 sementes por metro quadrado. Utilizou-se a cultivar de arroz de terras altas BRS Sertaneja e adubação no sulco de 
semeadura de $300 \mathrm{~kg} \mathrm{ha}^{-1}$ da formulação 08-20-18. A adubação de cobertura foi feita aos 40 dias após a semeadura (DAS) do arroz, com $60 \mathrm{~kg} \mathrm{ha}^{-1}$ de $\mathrm{N}$ na forma de ureia, aplicada a lanço em superfície.

No primeiro ano, o milheto sofreu uma dessecação anterior à realizada em 21/10/2008, aos 60 dias após a semeadura (22/5/2008), no estádio fenológico de pleno florescimento, tendo-se utilizado o herbicida glifosato (1.468 $\mathrm{g} \mathrm{ha}^{-1}$ e.a.). No segundo ano (safra 2009/2010), entretanto, o milheto foi dessecado apenas ao final da entressafra (17/11/2009).

A colheita do arroz ocorreu em 31/3/2009, e a semeadura das plantas de cobertura do segundo ano do experimento, em 7/4/2009. Aos 220 dias após a semeadura, em 17/11/2009, realizou-se a dessecação. Após 33 dias, em 21/12/2009, a soja, cultivar BRS Valiosa RR, foi semeada em plantio direto, com espaçamento de $0,45 \mathrm{~m}$, estande final de $350 \mathrm{mil}$ plantas por hectare e adubação na linha de semeadura de $400 \mathrm{~kg} \mathrm{ha}^{-1}$ da formulação 02:20:18.

Para a avaliação dos nutrientes remanescentes nas plantas de cobertura, as parcelas foram subdivididas no tempo, com seis épocas de avaliação: $0,15,30$, 60, 90 e 120 dias após a dessecação (21/10/2008 e 17/11/2009).

Para a avaliação da ciclagem de nutrientes, a fitomassa seca das plantas de cobertura foi coletada em todas as subparcelas, segundo metodologia proposta por Crusciol et al. (2005), que consiste no uso de quadrado de ferro com dimensões $0,5 \times 0,5 \mathrm{~m}\left(0,25 \mathrm{~m}^{2}\right)$. A parte aérea e os resíduos das plantas de cobertura foram coletados com duas repetições por subparcela. Em seguida, os resíduos foram submetidos à secagem em estufa com temperatura de $65^{\circ} \mathrm{C}$, por três dias. Por fim, realizou-se a limpeza manual dos resíduos, sem uso de água, para obtenção da fitomassa seca.

Os resíduos foram triturados em moinho tipo Willey (malha de $2 \mathrm{~mm}$ ), para posterior determinação das concentrações de N, P, K, Ca e Mg, conforme Nogueira et al. (2005). Para a determinação da relação $\mathrm{C} / \mathrm{N}$, no momento da dessecação, a concentração de carbono total nos tecidos vegetais foi quantificada por método colorimétrico (Cantarella et al., 2001).

Para descrever a liberação de nutrientes, os dados foram ajustados ao modelo exponencial, descrito por Wieder \& Lang (1982), $\mathrm{P}_{\mathrm{L}}=$ Po $\exp (-\mathrm{kt})$ e $\mathrm{P}_{\mathrm{L}}=\mathrm{Co}+\mathrm{Po} \exp (-\mathrm{kt})$, em que: $\mathrm{P}_{\mathrm{L}}$ é a quantidade de nutrientes existentes no tempo t $\left(\mathrm{kg} \mathrm{ha}^{-1}\right)$; Co é uma constante de ajuste do modelo; Po é a fração de nutrientes potencialmente liberados $\left(\mathrm{kg} \mathrm{ha}^{-1}\right)$; e k é a taxa de liberação de nutrientes $\left(\mathrm{g} \mathrm{g}^{-1}\right)$. Com o valor de $\mathrm{k}$, calculou-se o tempo de meia-vida ( $\mathrm{T}^{1} / 2$ vida) dos nutrientes, com uso da fórmula proposta por Paul \& Clark (1989): $\mathrm{T}^{1} / 2$ vida $=0,693 / \mathrm{k}$.

As colheitas do arroz e da soja foram realizadas em 31/3/2009 e 16/4/2010, respectivamente, e quantificadas por meio de amostragens em $5 \mathrm{~m}^{2}$, coletadas na parte central das parcelas. A produtividade

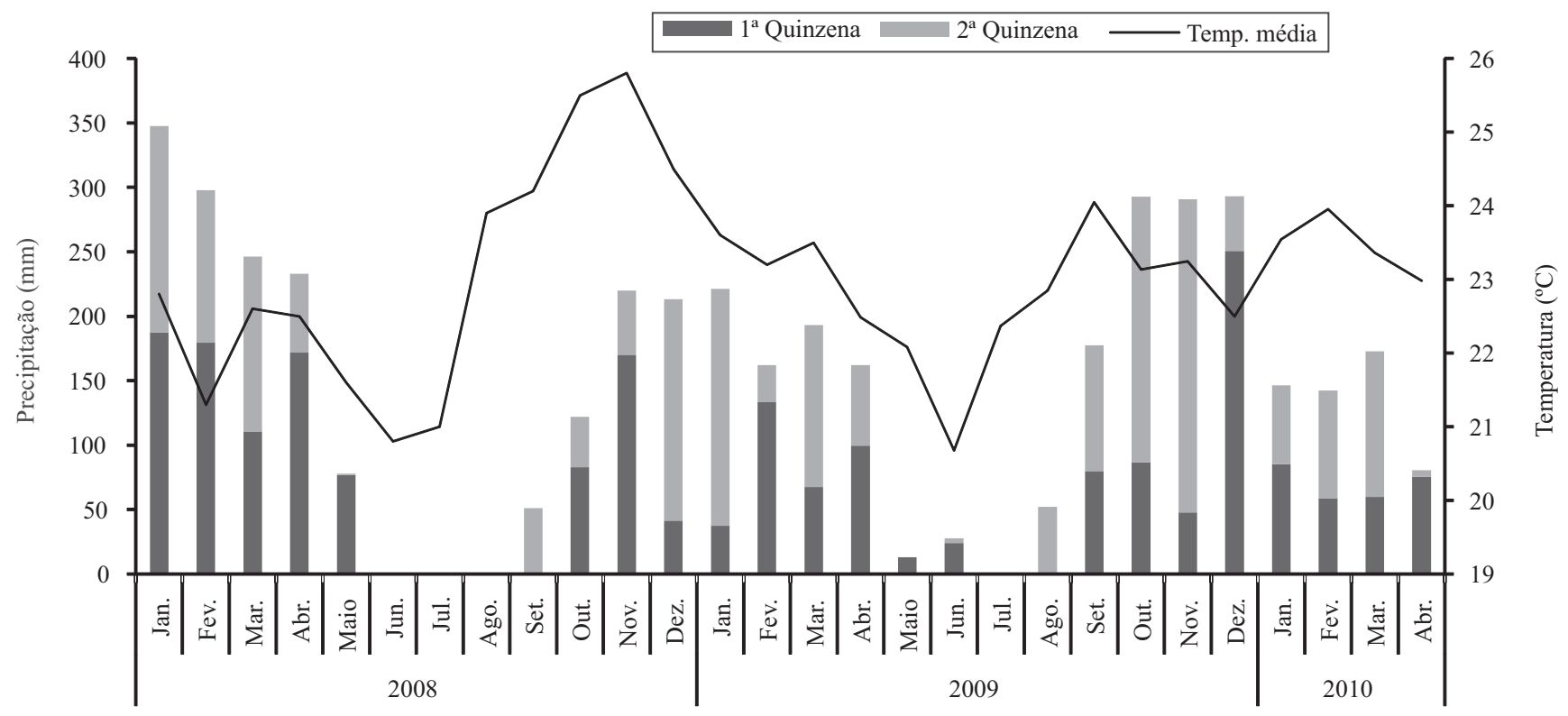

Figura 1. Precipitação e temperatura média em Santo Antônio de Goiás, GO, durante a condução do experimento. 
de grãos foi corrigida para $13 \%$ de umidade e expressa em $\mathrm{kg} \mathrm{ha}^{-1}$.

Os resultados foram submetidos à análise de variância e as médias qualitativas foram comparadas pelo teste de Tukey, a $5 \%$ de probabilidade. As equações de regressão foram ajustadas aos dados quantitativos, de acordo com o tempo, com auxílio do programa Sigma Plot, versão 10.0 (Systat Software Inc., San Jose, CA, EUA). As equações de regressão foram comparadas após linearização, segundo Snedecor \& Cochran (1989).

\section{Resultados e Discussão}

Na safra 2008/2009, a produção de fitomassa seca das plantas de cobertura e do pousio, no momento da dessecação, foi de: U. ruziziensis, $6.700 \mathrm{~kg} \mathrm{ha}^{-1}$; $U$. brizantha, $9.700 \mathrm{~kg} \mathrm{ha}^{-1}$; U. ruziziensis $+C$. cajan, $8.000 \mathrm{~kg} \mathrm{ha}^{-1}$; e pousio, $1.800 \mathrm{~kg} \mathrm{ha}^{-1}$. Na safra 2009/2010, esses valores foram de: U. ruziziensis, $13.900 \mathrm{~kg} \mathrm{ha}{ }^{-1} ; \quad$. brizantha, $15.400 \mathrm{~kg} \mathrm{ha}{ }^{-1}$; U. ruziziensis + C. cajan, $15.000 \mathrm{~kg} \mathrm{ha}^{-1}$; e pousio, $6.200 \mathrm{~kg} \mathrm{ha}^{-1}$. Esses resultados estão de acordo com as médias observadas para a região, conforme Pacheco et al. (2008, 2011a, 2011b). É importante destacar que as condições meteorológicas durante o crescimento das plantas de cobertura e pousio (final da entressafra e início da safra seguinte) foram normais, frente às médias observadas na região, e mais abundantes na segunda safra.

Com relação ao acúmulo de nutrientes nos resíduos vegetais, observou-se efeito da interação entre cobertura do solo e época de avaliação (Tabela 1). As espécies $U$. brizantha, U. ruziziensis e $U$.ruziziensis $+C$. cajan apresentaram os maiores acúmulos de $\mathrm{N}, \mathrm{P}, \mathrm{K}, \mathrm{Ca}$ e $\mathrm{Mg}$ no final do período de avaliação, em razão da elevada capacidade de produção de fitomassa após o reinício das precipitações, em setembro (Figura 1).

$\mathrm{Na}$ safra 2008/2009, as quantidades acumuladas de $\mathrm{N}$ e K, entre 0 e 15 dias após a dessecação (DAD), aumentaram em $U$. brizantha pela falha na dessecação, o que possibilitou a continuação do desenvolvimento da espécie. Não foi realizada nova dessecação de manejo, uma vez que o arroz de terras altas havia sido semeado antes da constatação da ineficiência da aplicação do herbicida. Na safra seguinte, entretanto, a dessecação de manejo foi mais eficiente, o que evitou a rebrota e promoveu o aumento na liberação dos nutrientes nos resíduos vegetais da espécie. Constantin et al. (2008) já relataram a dificuldade de controle de espécies de Urochloa pelo herbicida glifosato.

Tabela 1. Nutrientes remanescentes na fitomassa das plantas de cobertura e no pousio, avaliados em seis épocas após a dessecação, antes da semeadura do arroz de terras altas $(2008 / 2009)$ em plantio direto ${ }^{(1)}$.

\begin{tabular}{|c|c|c|c|c|c|}
\hline $\begin{array}{l}\text { Época }{ }^{(2)} \\
\text { (dias) }\end{array}$ & $\begin{array}{l}\text { Urochloa } \\
\text { ruziziensis }\end{array}$ & U. brizantha & $\begin{array}{l}\text { Pennisetum } \\
\text { glaucum }^{(3)}\end{array}$ & $\begin{array}{l}\text { U. ruzizensis }+ \\
\text { Cajanus cajan }\end{array}$ & Pousio \\
\hline & \multicolumn{5}{|c|}{ Nitrogênio $\left(\mathrm{kg} \mathrm{ha}^{-1}\right)$} \\
\hline 0 & $144,13 \mathrm{a}$ & $135,14 \mathrm{a}$ & $40,63 b$ & $149,02 \mathrm{a}$ & $35,83 b$ \\
\hline 15 & $103,01 b$ & $167,32 \mathrm{a}$ & $38,32 \mathrm{c}$ & $107,82 b$ & $25,14 \mathrm{c}$ \\
\hline 30 & $78,61 \mathrm{a}$ & $81,79 a$ & $35,98 b$ & $83,20 \mathrm{a}$ & $18,97 \mathrm{~b}$ \\
\hline 60 & $65,26 \mathrm{a}$ & $79,39 a$ & $31,12 \mathrm{bc}$ & $45,84 b$ & $19,61 \mathrm{c}$ \\
\hline 90 & $46,88 \mathrm{~b}$ & $66,64 a$ & $25,41 \mathrm{c}$ & $37,94 \mathrm{bc}$ & $8,60 \mathrm{~d}$ \\
\hline 120 & $40,62 \mathrm{a}$ & $52,05 \mathrm{a}$ & $26,09 b$ & $25,97 b$ & $9,15 \mathrm{c}$ \\
\hline \multirow[t]{2}{*}{$\mathrm{CV}(\%)$} & & & 16,5 & & \\
\hline & \multicolumn{5}{|c|}{ Fósforo $\left(\mathrm{kg} \mathrm{ha}^{-1}\right)$} \\
\hline 0 & $12,45 \mathrm{a}$ & $12,88 \mathrm{a}$ & $6,98 b$ & $13,56 \mathrm{a}$ & $4,14 b$ \\
\hline 15 & $7,15 \mathrm{ab}$ & $8,83 \mathrm{a}$ & $4,92 b$ & $7,23 \mathrm{ab}$ & $2,43 \mathrm{c}$ \\
\hline 30 & $3,31 \mathrm{bc}$ & $5,09 \mathrm{a}$ & $2,19 \mathrm{~cd}$ & 4,09ab & $1,28 \mathrm{~d}$ \\
\hline 60 & $2,96 \mathrm{a}$ & $3,24 \mathrm{a}$ & $1,42 \mathrm{~cd}$ & $2,48 b$ & $1,04 d$ \\
\hline 90 & $1,94 \mathrm{a}$ & $2,43 \mathrm{a}$ & $1,00 \mathrm{~b}$ & $1,86 \mathrm{a}$ & $0,56 \mathrm{~b}$ \\
\hline 120 & $2,23 \mathrm{a}$ & $1,48 b$ & $0,94 \mathrm{c}$ & $1,74 \mathrm{ab}$ & $0,39 d$ \\
\hline \multirow[t]{2}{*}{$\mathrm{CV}(\%)$} & & & 21,2 & & \\
\hline & \multicolumn{5}{|c|}{ Potássio $\left(\mathrm{kg} \mathrm{ha}^{-1}\right)$} \\
\hline 0 & $118,97 \mathrm{a}$ & $118,11 \mathrm{a}$ & $31,94 b$ & $119,91 \mathrm{a}$ & $26,84 b$ \\
\hline 15 & $52,53 b$ & $222,98 \mathrm{a}$ & $30,34 \mathrm{c}$ & $56,33 b$ & $19,68 \mathrm{c}$ \\
\hline 30 & $45,78 b$ & $73,36 a$ & $25,20 \mathrm{c}$ & $41,50 \mathrm{~b}$ & $18,39 \mathrm{c}$ \\
\hline 60 & $32,94 a$ & $39,70 \mathrm{a}$ & $14,02 \mathrm{~b}$ & $20,96 b$ & $13,04 b$ \\
\hline 90 & $25,64 a$ & $21,25 \mathrm{a}$ & $10,26 b c$ & $18,39 \mathrm{ab}$ & $7,03 \mathrm{c}$ \\
\hline 120 & $23,27 \mathrm{a}$ & $17,17 \mathrm{~b}$ & $8,65 \mathrm{c}$ & $16,34 b$ & $7,12 \mathrm{c}$ \\
\hline \multirow[t]{2}{*}{$\mathrm{CV}(\%)$} & & & 18,3 & & \\
\hline & \multicolumn{5}{|c|}{ Cálcio $\left(\mathrm{kg} \mathrm{ha}^{-1}\right)$} \\
\hline 0 & $63,37 b$ & $86,91 \mathrm{a}$ & $26,92 \mathrm{c}$ & $92,32 \mathrm{a}$ & $27,15 \mathrm{c}$ \\
\hline 15 & $43,62 b$ & $79,03 \mathrm{a}$ & $24,59 \mathrm{c}$ & $51,50 \mathrm{~b}$ & $18,03 \mathrm{c}$ \\
\hline 30 & $43,00 \mathrm{ab}$ & $52,45 \mathrm{a}$ & $18,75 \mathrm{c}$ & $35,24 b$ & $9,06 \mathrm{c}$ \\
\hline 60 & $37,76 \mathrm{a}$ & $40,19 \mathrm{a}$ & $15,64 b c$ & $25,50 \mathrm{~b}$ & $7,11 \mathrm{c}$ \\
\hline 90 & $17,52 \mathrm{a}$ & $11,74 b$ & $14,47 \mathrm{ab}$ & $13,13 b$ & $4,99 \mathrm{c}$ \\
\hline 120 & $14,19 \mathrm{a}$ & $9,69 \mathrm{bc}$ & $15,54 \mathrm{a}$ & $10,08 \mathrm{bc}$ & $6,21 \mathrm{c}$ \\
\hline \multirow[t]{2}{*}{$\mathrm{CV}(\%)$} & & & 23,1 & & \\
\hline & \multicolumn{5}{|c|}{ Magnésio $\left(\mathrm{kg} \mathrm{ha}^{-1}\right)$} \\
\hline 0 & $37,11 \mathrm{a}$ & $45,42 \mathrm{a}$ & $15,08 \mathrm{~b}$ & $34,68 \mathrm{a}$ & $15,25 b$ \\
\hline 15 & $24,76 b$ & $41,94 a$ & $13,89 \mathrm{c}$ & $25,37 b$ & $11,22 \mathrm{c}$ \\
\hline 30 & $21,90 \mathrm{~b}$ & $32,04 \mathrm{a}$ & $11,85 \mathrm{c}$ & $16,21 b c$ & $9,38 \mathrm{c}$ \\
\hline 60 & $15,11 \mathrm{a}$ & $16,36 \mathrm{a}$ & $10,84 b$ & $6,79 \mathrm{c}$ & $4,92 \mathrm{c}$ \\
\hline 90 & $7,92 b$ & $12,31 \mathrm{a}$ & $5,40 \mathrm{~b}$ & $2,30 \mathrm{c}$ & $1,37 \mathrm{c}$ \\
\hline 120 & $5,77 \mathrm{ab}$ & $7,34 \mathrm{a}$ & $3,06 \mathrm{bc}$ & $3,78 \mathrm{bc}$ & $1,26 \mathrm{c}$ \\
\hline CV (\%) & & & 20,6 & & \\
\hline
\end{tabular}

${ }^{(1)}$ Médias seguidas de letras iguais, nas linhas, não diferem pelo teste de Tukey, a $5 \%$ de probabilidade. ${ }^{(2)}$ Época de avaliação dos resíduos, em dias após a dessecação. ${ }^{(3)}$ Pennisetum glaucum foi dessecado no florescimento, com produção de $3.400 \mathrm{~kg} \mathrm{ha}^{-1}$ de fitomassa seca. 
O elevado aumento no acúmulo de $\mathrm{P}$ das espécies, no segundo ano (Tabela 2), pode ser explicado pela ocorrência de precipitações mais abundantes e

Tabela 2. Nutrientes remanescentes na fitomassa das plantas de cobertura e no pousio, avaliados em seis épocas após a dessecação, antes da semeadura da soja (2009/2010) em plantio direto $^{(1)}$.

\begin{tabular}{|c|c|c|c|c|c|}
\hline Época $^{(2)}$ & $\begin{array}{c}\text { Urochloa } \\
\text { ruziziensis }\end{array}$ & U. brizantha & $\begin{array}{l}\text { Pennisetum } \\
\text { glaucum }^{(3)}\end{array}$ & $\begin{array}{l}\text { U. ruzizensis }+ \\
\text { Cajanus cajan }\end{array}$ & Pousio \\
\hline & \multicolumn{5}{|c|}{ Nitrogênio $\left(\mathrm{kg} \mathrm{ha}^{-1}\right)$} \\
\hline 0 & $161,7 \mathrm{~A}$ & $164,7 \mathrm{~A}$ & $87,3 \mathrm{~B}$ & $157,9 \mathrm{~A}$ & $79,1 \mathrm{~B}$ \\
\hline 15 & $154,4 \mathrm{~A}$ & $160,7 \mathrm{~A}$ & $83,7 \mathrm{~B}$ & $143,8 \mathrm{~A}$ & $70,5 \mathrm{~B}$ \\
\hline 30 & $131,8 \mathrm{~A}$ & $138,9 \mathrm{~A}$ & $78,0 \mathrm{~B}$ & $141,9 \mathrm{~A}$ & $61,4 \mathrm{~B}$ \\
\hline 60 & $99,3 \mathrm{AB}$ & $124,8 \mathrm{~A}$ & $75,6 \mathrm{~B}$ & $116,8 \mathrm{~A}$ & $60,6 \mathrm{~B}$ \\
\hline 90 & $90,7 \mathrm{AB}$ & $125,6 \mathrm{~A}$ & $66,2 \mathrm{~B}$ & $88,0 \mathrm{AB}$ & $60,5 \mathrm{~B}$ \\
\hline 120 & $89,1 \mathrm{~A}$ & $90,5 \mathrm{~A}$ & $63,9 \mathrm{~B}$ & $86,4 \mathrm{~A}$ & $60,5 \mathrm{~B}$ \\
\hline \multirow[t]{2}{*}{ CV (\%) } & \multicolumn{5}{|c|}{13,73} \\
\hline & \multicolumn{5}{|c|}{ Fósforo $\left(\mathrm{kg} \mathrm{ha}^{-1}\right)$} \\
\hline 0 & $43,8 b$ & $44,8 \mathrm{ab}$ & $21,8 \mathrm{c}$ & $53,1 \mathrm{a}$ & $30,0 \mathrm{c}$ \\
\hline 15 & $45,1 \mathrm{a}$ & $34,9 b c$ & $20,7 d$ & $40,5 \mathrm{ab}$ & $27,7 \mathrm{~cd}$ \\
\hline 30 & $35,6 \mathrm{a}$ & $30,9 \mathrm{ab}$ & $18,9 \mathrm{c}$ & $32,2 \mathrm{ab}$ & $24,8 \mathrm{bc}$ \\
\hline 60 & $33,8 \mathrm{a}$ & $31,8 \mathrm{a}$ & $14,5 \mathrm{bc}$ & $22,9 b$ & $13,2 \mathrm{c}$ \\
\hline 90 & $20,2 \mathrm{a}$ & $20,7 \mathrm{a}$ & $13,7 \mathrm{a}$ & $14,2 \mathrm{a}$ & $13,1 \mathrm{a}$ \\
\hline 120 & $19,1 \mathrm{a}$ & $18,9 \mathrm{a}$ & $9,9 \mathrm{~b}$ & $13,3 \mathrm{ab}$ & $12,2 \mathrm{ab}$ \\
\hline \multirow[t]{2}{*}{ CV (\%) } & \multicolumn{5}{|c|}{16,82} \\
\hline & \multicolumn{5}{|c|}{ Potássio $\left(\mathrm{kg} \mathrm{ha}^{-1}\right)$} \\
\hline 0 & $210,8 b$ & $246,4 a$ & $115,2 \mathrm{c}$ & $195,0 \mathrm{~b}$ & $85,2 \mathrm{~d}$ \\
\hline 15 & $173,9 \mathrm{a}$ & $148,9 \mathrm{a}$ & $105,0 \mathrm{~b}$ & $156,6 \mathrm{a}$ & $84,6 \mathrm{~b}$ \\
\hline 30 & $157,7 \mathrm{a}$ & $106,5 b$ & $67,6 \mathrm{c}$ & $110,8 b$ & $68,1 \mathrm{c}$ \\
\hline 60 & $78,3 \mathrm{ab}$ & $74,5 \mathrm{abc}$ & $51,6 \mathrm{bc}$ & $85,1 \mathrm{a}$ & $48,0 \mathrm{c}$ \\
\hline 90 & $70,1 \mathrm{ab}$ & $78,9 \mathrm{a}$ & $48,6 b$ & $57,3 \mathrm{ab}$ & $45,9 b$ \\
\hline 120 & $63,1 \mathrm{a}$ & $64,4 \mathrm{a}$ & $40,9 \mathrm{a}$ & $56,2 \mathrm{a}$ & $42,1 \mathrm{a}$ \\
\hline \multirow[t]{2}{*}{ CV (\%) } & \multicolumn{5}{|c|}{15,41} \\
\hline & \multicolumn{5}{|c|}{ Cálcio $\left(\mathrm{kg} \mathrm{ha}^{-1}\right)$} \\
\hline 0 & $110,9 a$ & $77,0 \mathrm{~b}$ & $48,8 \mathrm{c}$ & $90,0 \mathrm{~b}$ & $55,0 \mathrm{c}$ \\
\hline 15 & $76,4 a$ & $65,2 \mathrm{ab}$ & $44,1 \mathrm{c}$ & $69,3 \mathrm{ab}$ & $54,0 \mathrm{bc}$ \\
\hline 30 & $82,4 a$ & $69,4 a$ & $39,0 \mathrm{~b}$ & $60,8 \mathrm{a}$ & $42,5 b$ \\
\hline 60 & $57,3 \mathrm{a}$ & $55,9 \mathrm{a}$ & $50,4 \mathrm{ab}$ & $59,4 \mathrm{a}$ & $36,0 \mathrm{~b}$ \\
\hline 90 & $52,6 \mathrm{a}$ & $44,8 \mathrm{a}$ & $18,2 b$ & $42,9 a$ & $40,1 \mathrm{a}$ \\
\hline 120 & $45,1 \mathrm{ab}$ & $38,3 \mathrm{~b}$ & $34,9 \mathrm{~b}$ & $61,7 \mathrm{a}$ & $30,7 \mathrm{~b}$ \\
\hline \multirow[t]{2}{*}{ CV (\%) } & \multicolumn{5}{|c|}{15,98} \\
\hline & \multicolumn{5}{|c|}{ Magnésio $\left(\mathrm{kg} \mathrm{ha}^{-1}\right)$} \\
\hline 0 & $27,7 \mathrm{a}$ & $30,8 \mathrm{a}$ & $17,2 b$ & $30,0 \mathrm{a}$ & $16,0 \mathrm{~b}$ \\
\hline 15 & $24,5 \mathrm{a}$ & $26,1 \mathrm{a}$ & $14,2 \mathrm{~b}$ & $25,7 \mathrm{a}$ & $12,3 \mathrm{~b}$ \\
\hline 30 & $23,5 \mathrm{a}$ & $23,1 \mathrm{a}$ & $13,0 \mathrm{~b}$ & $23,1 \mathrm{a}$ & $12,1 \mathrm{~b}$ \\
\hline 60 & $19,1 \mathrm{a}$ & $18,6 \mathrm{a}$ & $6,3 b$ & $9,9 b$ & $6,0 \mathrm{~b}$ \\
\hline 90 & $8,7 \mathrm{a}$ & $10,0 \mathrm{a}$ & $6,1 \mathrm{a}$ & $7,2 \mathrm{a}$ & $5,7 \mathrm{a}$ \\
\hline 120 & $13,2 \mathrm{a}$ & $14,3 \mathrm{a}$ & $5,0 \mathrm{~b}$ & $6,9 b$ & $5,2 \mathrm{~b}$ \\
\hline CV (\%) & & & 14,44 & & \\
\hline
\end{tabular}

${ }^{(1)}$ Médias seguidas de letras iguais, nas linhas, não diferem pelo teste de Tukey, a 5\% de probabilidade. (2)Época de avaliação dos resíduos, em dias após a dessecação. ${ }^{(3)}$ Pennisetum glaucum foi dessecado no florescimento, com produção de $3.400 \mathrm{~kg} \mathrm{ha}^{-1}$ de fitomassa seca. regulares durante a entressafra, o que acarretou maior crescimento das plantas e absorção desse nutriente. O maior crescimento das plantas pode ser atestado pela maior produção de fitomassa, no segundo ano.

As espécies $U$. brizantha e U. ruziziensis, solteira ou consorciada com C. cajan (Tabelas 1 e 2), destacaramse no acúmulo de nutrientes, principalmente quando semeadas no final das chuvas de verão (março/abril), após a colheita da cultura da soja e do arroz. Pennisetum glaucum, por apresentar decomposição rápida em comparação às demais plantas de cobertura, resultou em baixas quantidades de nutrientes remanescentes no momento da dessecação para a semeadura das culturas anuais. Os menores teores de nutrientes acumulados em P. glaucum, no primeiro ano (safra 2008/2009), podem ser explicados pela realização da dessecação de manejo com glifosato em plena entressafra, por ocasião do florescimento das plantas, o que favoreceu a antecipação da decomposição da fitomassa e da liberação de nutrientes. Vale ressaltar que os demais tratamentos somente foram dessecados ao final da entressafra. Dessa forma, a baixa quantidade de nutrientes potencialmente mineralizáveis na palhada que sofreu dessecação precoce indica que esta prática não deve ser recomendada. Além disso, a dessecação somente ao final da entressafra apresenta ainda a vantagem de as sementes produzidas pelo milheto não dessecado, durante a entressafra, germinarem e darem origem a novas plantas após o reinício das chuvas de verão, em setembro/outubro, com significativo incremento de fitomassa e nutrientes.

Os nutrientes que apresentaram maior acúmulo na fitomassa foram N, K, Ca, P e Mg, de até 164, 246, 110,53 e $45 \mathrm{~kg} \mathrm{ha}^{-1}$, respectivamente. Esses resultados corroboram os obtidos por Torres et al. (2008), que apontaram maior potencial de ciclagem de $\mathrm{N}$ e $\mathrm{K}$ pelas plantas de cobertura. Pacheco et al. (2011b) observaram que $U$. ruziziensis e $P$. glaucum apresentam potencial para acumular em torno de $116 \mathrm{~kg} \mathrm{ha}^{-1}$ de K e $102 \mathrm{~kg} \mathrm{ha}^{-1}$ de $\mathrm{N}$, quando semeadas na entressafra, em Rio Verde, GO. Ao considerar o elevado custo dos fertilizantes, é possível que o uso contínuo de plantas de cobertura, nos sistemas agrícolas de produção de soja e arroz, proporcione o uso mais eficiente dos nutrientes disponíveis no solo, com reflexos favoráveis sobre o custo de produção. Carneiro et al. (2009) demonstraram a potencialidade do uso de $U$. decumbens e $P$. glaucum, em sistemas de rotação com soja, milho e arroz, na 
melhoria dos atributos químicos, físicos e biológicos do solo nos Cerrados dos estados de Mato Grosso do Sul e de Goiás.

Os coeficientes das equações ajustadas para a descrição da liberação de nutrientes da fitomassa estão apresentados nas Tabelas 3 e 4. Em todas as plantas de cobertura estudadas, a equação exponencial decrescente foi a que apresentou melhor ajuste, com elevadas taxas de liberação de nutrientes nos primeiros 30 a 40 dias após a dessecação. Estes resultados estão de acordo com Pacheco et al. (2011a). As espécies U. ruziziensis + C. cajan, seguidas por U. ruziziensis, apresentaram as maiores taxas de liberação, para a maioria dos nutrientes avaliados, o que fez com que tivessem os

Tabela 3. Coeficientes da equação de regressão ${ }^{(1)}$ para N, $\mathrm{P}, \mathrm{K}, \mathrm{Ca}$ e $\mathrm{Mg}$ remanescentes nos resíduos das plantas de cobertura, avaliadas em seis épocas após a dessecação, antes da semeadura do arroz de terras altas (2008/2009).

\begin{tabular}{|c|c|c|c|c|c|}
\hline Época & $\begin{array}{l}\text { Urochloa } \\
\text { ruziziensis }\end{array}$ & U. brizantha & $\begin{array}{l}\text { Pennisetum } \\
\text { glaucum }^{(2)}\end{array}$ & $\begin{array}{l}\text { U. ruzizensis }+ \\
\text { Cajanus cajan }\end{array}$ & Pousio \\
\hline & & & Nitrogênio & & \\
\hline Po $\left(\mathrm{kg} \mathrm{ha}^{-1}\right)$ & 132,24 & 147,47 & 40,58 & 144,08 & 33,09 \\
\hline $\mathrm{k}\left(\mathrm{g} \mathrm{g}^{-1}\right)$ & 0,0121 & 0,0094 & 0,0043 & 0,0170 & 0,0126 \\
\hline $\mathrm{R}^{2}$ & $0,93 * *$ & $0,73^{*}$ & $0,95^{* *}$ & $0,98^{* *}$ & $0,90^{* *}$ \\
\hline \multirow[t]{2}{*}{$\mathrm{T}^{1} / 2$ (dias) } & 57 & 74 & 161 & 40 & 55 \\
\hline & & & Fósforo & & \\
\hline Po $\left(\mathrm{kg} \mathrm{ha}^{-1}\right)$ & 11,83 & 12,50 & 6,92 & 13,04 & 3,96 \\
\hline $\mathrm{k}\left(\mathrm{g} \mathrm{g}^{-1}\right)$ & 0,0297 & 0,0235 & 0,0277 & 0,0332 & 0,0288 \\
\hline $\mathrm{R}^{2}$ & $0,89 * *$ & $0,97 * *$ & $0,95^{* *}$ & $0,94^{* *}$ & $0,95^{* *}$ \\
\hline \multirow[t]{2}{*}{$\mathrm{T}^{1 / 2}$ (dias) } & 24 & 30 & 25 & 21 & 24 \\
\hline & & & Potássio & & \\
\hline Co $\left(\mathrm{kg} \mathrm{ha}^{-1}\right)$ & 27,84 & $\mathrm{~ns}$ & 1,88 & 17,84 & 3,06 \\
\hline Po $\left(\mathrm{kg} \mathrm{ha}^{-1}\right)$ & 90,12 & $\mathrm{~ns}$ & 35,60 & 101,12 & 23,19 \\
\hline $\mathrm{k}\left(\mathrm{g} \mathrm{g}^{-1}\right)$ & 0,0724 & $\mathrm{~ns}$ & 0,0112 & 0,0570 & 0,0159 \\
\hline $\mathrm{R}^{2}$ & $0,98 * *$ & $\mathrm{~ns}$ & $0,97 * *$ & $0,99 * *$ & $0,97 * *$ \\
\hline \multirow[t]{2}{*}{$\mathrm{T}^{1 / 2}$ (dias) } & 9 & - & 62 & 12 & 43 \\
\hline & & & Cálcio & & \\
\hline Po $\left(\mathrm{kg} \mathrm{ha}^{-1}\right)$ & 60,07 & 91,84 & 25,43 & 86,51 & 25,61 \\
\hline $\mathrm{k}\left(\mathrm{g} \mathrm{g}^{-1}\right)$ & 0,0115 & 0,0170 & 0,0058 & 0,0251 & 0,0226 \\
\hline $\mathrm{R}^{2}$ & $0,92 * *$ & $0,96^{* *}$ & $0,83^{*}$ & $0,96^{* *}$ & $0,89 * *$ \\
\hline \multirow[t]{2}{*}{$\mathrm{T}^{1} / 2$ (dias) } & 60 & 41 & 119 & 27 & 31 \\
\hline & & & Magnésio & & \\
\hline Po $\left(\mathrm{kg} \mathrm{ha}^{-1}\right)$ & 35,30 & 48,14 & 15,92 & 35,27 & 15,48 \\
\hline $\mathrm{k}\left(\mathrm{g} \mathrm{g}^{-1}\right)$ & 0,0159 & 0,0153 & 0,0104 & 0,0255 & 0,0202 \\
\hline $\mathrm{R}^{2}$ & $0,98 * *$ & $0,98 * *$ & $0,92 * *$ & $0,99 * *$ & $0,99 * *$ \\
\hline $\mathrm{T}^{1} / 2$ (dias) & 43 & 45 & 67 & 27 & 34 \\
\hline
\end{tabular}

${ }^{(1)} \mathrm{P}_{\mathrm{L}}=\mathrm{P}_{\mathrm{o}} \exp (-\mathrm{kt})$ ou $\mathrm{P}_{\mathrm{L}}=\mathrm{Co}+\mathrm{Po} \exp (-\mathrm{kt})$, em que: $\mathrm{P}_{\mathrm{L}}$ é a quantidade de nutrientes existentes no tempo $\mathrm{t}\left(\mathrm{kg} \mathrm{ha}^{-1}\right)$; Co é uma constante de ajuste do modelo; Po é a fração de nutrientes potencialmente liberados $\left(\mathrm{kg} \mathrm{ha}^{-1}\right) ; \mathrm{k}^{\mathrm{e}}$ a taxa de liberação de nutrientes $\left(\mathrm{g} \mathrm{g}^{-1}\right)$; e $\mathrm{T}^{1 / 2} \mathrm{e}$ é a meia-vida. (2) Pennisetum glaucum foi dessecado no florescimento. ns Não significativo. * e **Significativo a 5 e $1 \%$ de probabilidade, respectivamente. menores tempos de meia-vida. Carvalho et al. (2011) atribuíram a elevada taxa de decomposição e liberação de nutrientes da fitomassa de $U$. ruziziensis aos baixos teores de lignina e celulose da espécie (3,67 e 10,95\%, respectivamente). Pacheco et al. (2011b), em estudo com as mesmas plantas de cobertura que as do presente trabalho, em Rio Verde, GO, observaram os seguintes tempos de meia-vida: N, de 19 a 29 dias; P, de 12 a 15 dias; $\mathrm{K}$, de 10 a 11 dias; $\mathrm{Ca}$, de 67 dias; e $\mathrm{Mg}$, de 22 a 49 dias. Esses resultados confirmam o potencial das espécies $U$. ruziziensis $+C$. cajan, seguidas por U. ruziziensis, na produção de fitomassa e na ciclagem de nutrientes no solo. Os maiores tempos de meia-vida

Tabela 4. Coeficientes da equação de regressão ${ }^{(1)}$ para N, $\mathrm{P}, \mathrm{K}, \mathrm{Ca}$ e $\mathrm{Mg}$ remanescentes nos resíduos das plantas de cobertura, avaliadas em seis épocas após a dessecação, antes da semeadura da soja (2009/2010).

\begin{tabular}{|c|c|c|c|c|c|}
\hline Época & $\begin{array}{l}\text { Urochloa } \\
\text { ruziziensis }\end{array}$ & U. brizantha & $\begin{array}{l}\text { Pennisetum } \\
\text { glaucum }\end{array}$ & $\begin{array}{l}\text { U. ruzizensis + } \\
\text { Cajanus cajan }\end{array}$ & Pousio \\
\hline & & & Nitrogênio & & \\
\hline $\mathrm{Co}\left(\mathrm{kg} \mathrm{ha}^{-1}\right)$ & 72,03 & - & - & - & - \\
\hline Po $\left(\mathrm{kg} \mathrm{ha}^{-1}\right)$ & 94,99 & 165,78 & 86,68 & 159,36 & ns \\
\hline $\mathrm{k}\left(\mathrm{g} \mathrm{g}^{-1}\right)$ & 0,0168 & 0,0043 & 0,0027 & 0,0055 & $\mathrm{~ns}$ \\
\hline $\mathrm{R}^{2}$ & $0,96^{* *}$ & $0,91 * *$ & $0,97 * *$ & $0,96 * *$ & ns \\
\hline \multirow[t]{2}{*}{$\mathrm{T}^{1 / 2}(\mathrm{dias})$} & 41 & 161 & 256 & 126 & - \\
\hline & & & Fósforo & & \\
\hline Po $\left(\mathrm{kg} \mathrm{ha}^{-1}\right)$ & 46,45 & 41,83 & 22,27 & 51,18 & 30,62 \\
\hline $\mathrm{k}\left(\mathrm{g} \mathrm{g}^{-1}\right)$ & 0,0074 & 0,0069 & 0,0063 & 0,0135 & 0,0094 \\
\hline $\mathrm{R}^{2}$ & $0,92 * *$ & $0,89 * *$ & $0,97 * *$ & $0,98 * *$ & $0,92 * *$ \\
\hline \multirow[t]{2}{*}{$\mathrm{T}^{1 / 2}$ (dias) } & 93 & 100 & 110 & 51 & 73 \\
\hline & & & Potássio & & \\
\hline Co $\left(\mathrm{kg} \mathrm{ha}^{-1}\right)$ & 35,47 & 69,69 & 37,01 & 45,96 & 31,33 \\
\hline Po $\left(\mathrm{kg} \mathrm{ha}^{-1}\right)$ & 180,12 & 176,59 & 82,27 & 150,86 & 58,04 \\
\hline $\mathrm{k}\left(\mathrm{g} \mathrm{g}^{-1}\right)$ & 0,0179 & 0,0530 & 0,0255 & 0,0247 & 0,0157 \\
\hline $\mathrm{R}^{2}$ & $0,97 * *$ & $0,99 * *$ & $0,95^{* *}$ & $0,99 * *$ & $0,94 * *$ \\
\hline \multirow[t]{2}{*}{$\mathrm{T}^{1 / 2}$ (dias) } & 38 & 13 & 27 & 28 & 44 \\
\hline & & & Cálcio & & \\
\hline Co $\left(\mathrm{kg} \mathrm{ha}^{-1}\right)$ & 44,11 & - & - & 54,01 & - \\
\hline Po $\left(\mathrm{kg} \mathrm{ha}^{-1}\right)$ & 63,11 & 76,35 & ns & 35,86 & 56,66 \\
\hline $\mathrm{k}\left(\mathrm{g} \mathrm{g}^{-1}\right)$ & 0,0250 & 0,0056 & ns & 0,0547 & 0,0054 \\
\hline $\mathrm{R}^{2}$ & $0,92 *$ & $0,95 * *$ & ns & $0,83^{*}$ & $0,84 * *$ \\
\hline \multirow[t]{2}{*}{$\mathrm{T}^{1 / 2}$ (dias) } & 27 & 123 & - & 12 & 128 \\
\hline & & & Magnésio & & \\
\hline Po $\left(\mathrm{kg} \mathrm{ha}^{-1}\right)$ & 28,16 & 30,11 & 17,06 & 31,24 & 15,53 \\
\hline $\mathrm{k}\left(\mathrm{g} \mathrm{g}^{-1}\right)$ & 0,0081 & 0,0086 & 0,0120 & 0,0148 & 0,0114 \\
\hline $\mathrm{R}^{2}$ & 0,86 & $0,90 * *$ & $0,95^{* *}$ & $0,96 * *$ & $0,93 * *$ \\
\hline $\mathrm{T}^{1} / 2(\operatorname{dias})$ & 85 & 80 & 57 & 46 & 60 \\
\hline
\end{tabular}

${ }^{(1)} \mathrm{P}_{\mathrm{L}}=\mathrm{P}_{\mathrm{o}} \exp (-\mathrm{kt})$ ou $\mathrm{P}_{\mathrm{L}}=\mathrm{Co}+\mathrm{Po} \exp (-\mathrm{kt})$, em que: $\mathrm{P}_{\mathrm{L}}$ é a quantidade de nutrientes existentes no tempo $\mathrm{t}\left(\mathrm{kg} \mathrm{ha}^{-1}\right)$; Co é uma constante de ajuste do modelo; Po é a fração de nutrientes potencialmente liberados $\left(\mathrm{kg} \mathrm{ha}^{-1}\right) ; \mathrm{k}$ é a taxa de liberação de nutrientes $\left(\mathrm{g} \mathrm{g}^{-1}\right) ; \mathrm{e} \mathrm{T}^{1 / 2} 2$ é a meia-vida. ${ }^{\text {ns }}$ ão significativo. $*$ e **Significativo a 5 e $1 \%$ de probabilidade, respectivamente. 
obtidos no presente trabalho, em comparação aos encontrados por Pacheco et al. (2011b), podem ser justificados pelas condições edafoclimáticas do local, que apresentou menor pluviosidade e temperatura durante a condução dos ensaios.

Giacomini et al. (2003) relataram que o consórcio entre a gramínea aveia-preta (Avena strigosa) e a leguminosa ervilhaca comum (Vicia sativa) apresentou maior taxa de liberação de nutrientes que a aveia-preta solteira. Segundo esses autores, a menor relação $\mathrm{C} / \mathrm{N}$ $\mathrm{e}$, sobretudo, as maiores quantidades de nutrientes solúveis em água na leguminosa são fatores que podem interferir na liberação de nutrientes para as culturas anuais em sucessão. Espera-se que plantas de cobertura não apenas apresentem resistência à decomposição, mas que possibilitem a maior liberação possível de nutrientes para o solo, para que possam protege-lo e, ao mesmo tempo, favorecer o desenvolvimento das culturas anuais em sucessão. Nesse contexto, P. glaucum destaca-se por iniciar a liberação de nutrientes de forma antecipada e por apresentar ciclo fenológico precoce. A rápida liberação de nutrientes de $U$. ruziziensis, solteira ou consorciada com C. cajan, mostra o potencial dessa espécie em aumentar a disponibilidade de nutrientes no solo, para as culturas anuais.

Verificou-se maior velocidade de liberação dos nutrientes K e P (Tabelas 3 e 4), na safra 2008/2009 e 2009/2010. A rápida liberação de $K$, já nos primeiros 15 dias após a dessecação, pode ser atribuída às precipitações pluviais ocorridas e ao fato de que esse elemento não está associado a nenhum componente estrutural no tecido vegetal (Marschner, 1995). Quanto ao $\mathrm{P}$, a maior parte de seu conteúdo encontra-se no interior do vacúolo, na forma mineral, que tem alta capacidade de se solubilizar em água (Marschner, 1995).

Os resíduos do pousio apresentaram elevadas taxas de liberação de nutrientes ao solo, exceto para o K, no segundo ano (Tabela 2). Porém, a baixa produção de fitomassa desfavoreceu o acúmulo de nutrientes durante a entressafra, o que compromete a capacidade desta cobertura em ciclar nutrientes, em sistema plantio direto.

Ferrari Neto et al. (2012) constataram que, aos 91 dias após a dessecação, o consórcio de $P$. glaucum + C. cajan forneceu ao solo quantidades de nutrientes equivalentes a $191 \mathrm{~kg} \mathrm{ha}^{-1}$ de ureia $(44 \%$ de $\mathrm{N})$, $145 \mathrm{~kg} \mathrm{ha}^{-1}$ de superfosfato simples $\left(18 \%\right.$ de $\left.\mathrm{P}_{2} \mathrm{O}_{5}\right)$ e $245 \mathrm{~kg} \mathrm{ha}^{-1}$ de cloreto de potássio $\left(58 \%\right.$ de $\left.\mathrm{K}_{2} \mathrm{O}\right)$.
Contudo, esses autores não avaliaram o desempenho de culturas anuais em sucessão.

Observou-se efeito significativo das plantas de cobertura sobre a produtividade do arroz (Tabela 5). Urochloa ruziziensis foi a opção mais viável, por ter possibilitado a maior produtividade de arroz. Pacheco et al. (2011b), ao avaliar a produtividade de arroz de terras altas com o uso das mesmas plantas de cobertura que as do presente trabalho, também verificaram que $U$. ruziziensis possibilitou as maiores produtividades. Esses resultados comprovam a potencialidade dessa espécie para produção de fitomassa e ciclagem de nutrientes.

Apesar de $U$. brizantha ter apresentado elevado acúmulo de fitomassa, a decomposição e a liberação de nutrientes foi lenta, o que pode ter promovido maior imobilização de $\mathrm{N}$ pela microbiota do solo. Souza et al. (2006) mostraram que resíduos culturais de $U$. decumbens reduzem o crescimento inicial de plantas de arroz em plantio direto, em razão da menor disponibilidade de $\mathrm{N}$ no momento de maior exigência da cultura. De acordo com esses autores, os teores de $\mathrm{NO}_{3}{ }^{-}$, em plantio convencional, são maiores do que os observados no plantio direto. Os menores teores em plantio direto podem estar relacionados à inibição do processo de nitrificação por substâncias tóxicas, liberadas durante a decomposição.

A baixa produtividade do arroz pode ser explicada pela ocorrência de deficit hídrico, no estádio de pré-florescimento da cultura, período crítico quanto à disponibilidade hídrica no solo.

A soja, que não sofreu restrições ao seu desenvolvimento na safra 2009/2010, também não teve sua produtividade de grãos influenciada pelas diferentes plantas de cobertura (Tabela 5). Pacheco et al. (2011b) não observaram diferenças significativas na produtividade da soja sob as mesmas plantas de cobertura avaliadas no presente trabalho.

Tabela 5. Produtividade de grãos $\left(\mathrm{kg} \mathrm{ha}^{-1}\right)$ do arroz de terras altas e da soja após cultivo das plantas de cobertura e pousio.

\begin{tabular}{lcc}
\hline Espécie & Arroz (2008/2009) & Soja (2009/2010) \\
\hline Urochloa ruziziensis & $1.554 \mathrm{~A}$ & 2.961 \\
U. brizantha & $1.011 \mathrm{C}$ & 2.754 \\
Pennisetum glaucum & $1.444 \mathrm{AB}$ & 3.125 \\
U. ruziziensis + Cajanus cajan & $1.164 \mathrm{BC}$ & 2.943 \\
Pousio & $1.223 \mathrm{BC}$ & 2.784 \\
\hline CV $(\%)$ & 15,3 & 11,5 \\
\hline
\end{tabular}




\section{Conclusões}

1. Urochloa brizantha e U. ruziziensis, solteira ou consorciada com Cajanus cajan, proporcionam o maior acúmulo de nutrientes ao final da entressafra, o que, no entanto, não garante uma ciclagem eficiente dos nutrientes no solo.

2. Nitrogênio e potássio são os nutrientes mais acumulados, enquanto potássio e fósforo apresentam maior taxa de liberação.

3. Urochloa ruziziensis consiste na melhor opção de planta de cobertura para cultivo prévio à semeadura do arroz de terras altas, em plantio direto, embora nenhuma espécie tenha alterado significativamente a produtividade de grãos de soja.

\section{Agradecimentos}

À Fundação Agrisus, pelo apoio financeiro; à Coordenação de Aperfeiçoamento de Pessoal de Nível Superior (Capes), por bolsa; e ao Conselho Nacional de Desenvolvimento Científico e Tecnológico (CNPq), pelas bolsas de produtividade.

\section{Referências}

BRESEGHELLO, F.; MORAIS, O.P. de; PINHEIRO, P.V.; SILVA, A.C.S.; CASTRO, E.M.; PEREIRA, A.P.; LOPES, A.M.; UTUMI, M.M.; OLIVEIRA, J.P. Results of 25 years of upland rice breeding in Brazil. Crop Science, v.51, p.914-923, 2011. DOI: 10.2135/ cropsci2010.06.0325.

CANTARELlA, H.; QUAGGIO, H.C.; RAIJ, B. van. Determinação da matéria orgânica. In: RAIJ, B. van; ANDRADE, J.C. de; CANTEREllA, H.; QUAGGIO, J.A. (Ed.). Análise química para avaliação da fertilidade de solos tropicais. Campinas: Instituto Agronômico, 2001. p.173-188.

CARNEIRO, M.A.C.; SOUZA, E.D. de; REIS, E.F. dos; PEREIRA, H.S.; AZEVEDO, W.R. de. Atributos físicos, químicos e biológicos de solo de Cerrado sob diferentes sistemas de uso e manejo do solo. Revista Brasileira de Ciência do Solo, v.33, p.147-157, 2009. DOI: 10.1590/S0100-06832009000100016.

CARVALHO, A.M. de; SOUZA, L.L.P. de; GUIMARÃES JÚNIOR, R.; ALVES, P.C.A.C.; VIVALDI, L.J. Cover plants with potential use for crop-livestock integrated systems in the Cerrado region. Pesquisa Agropecuária Brasileira, v.46, p.1200-1205, 2011. DOI: 10.1590/S0100-204X2011001000012.

CONSTANTIN, J.; MACHADO, M.H.; CAVALIERI, S.D.; OLIVEIRA JUNIOR, R.S.; RIOS, F.A.; ROSO, A.C. Influência do glyphosate na dessecação de capim-braquiária e sobre o desenvolvimento inicial da cultura do milho. Planta Daninha, v.26, p.627-636, 2008. DOI: 10.1590/S0100-83582008000300019.
CRUSCIOL, C.A.C.; COTTICA, R.L.; LIMA, E. do V.; ANDREOTTI, M.; MORO, E.; MARCON, E. Persistência de palhada e liberação de nutrientes do nabo forrageiro no plantio direto. Pesquisa Agropecuária Brasileira, v.40, p.161-168, 2005. DOI: 10.1590/S0100-204X2005000200009.

FERRARI NETO, J.; CRUSCIOL, C.A.C.; SORATTO, R.P.; COSTA, C.H.M. da. Consórcio de guandu-anão com milheto: persistência e liberação de macronutrientes e silício da fitomassa. Bragantia, v.71, p.264-272, 2012. DOI: 10.1590/ S0006-87052012005000017.

GIACOMINI, S.J.; AITA, C.; HUBNER, A.P.; LUNKES, A.; GUIDINI, E.; AMARAL, E.B. do. Liberação de fósforo e potássio durante a decomposição de resíduos culturais em plantio direto. Pesquisa Agropecuária Brasileira, v.38, p.1097-1104, 2003. DOI: 10.1590/S0100-204X2003000900011.

KALBITZ, K.; SOLINGER, S.; PARK, J.H.; MATZNER, E. Controls on the dynamics of dissolved organic matter in soils: a review. Soil Science, v.165, p.277-304, 2000. DOI: 10.1097/0001 0694-200004000-00001.

KLUTHCOUSKI, J.; FANCELLI, A.L.; DOURADO-NETO, D.; RIBEIRO, C.M.; FERRARO, L.A. Manejo do solo e o rendimento de soja, milho, feijão e arroz em plantio direto. Scientia Agricola, v.57, p.97-104, 2000. DOI: 10.1590/S0103-90162000000100016.

MARSCHNER, H. Mineral nutrition of higher plants. $2^{\text {nd }} e d$. San Diego: Academic Press, 1995. 889p.

NOGUEIRA, A.R. de A.; CARMO, C.A.F.S.; MACHADO, P.L.O.A. Tecido vegetal. In: NOGUEIRA, A.R. de A.; SOUZA, G.B. de (Ed.). Manual de laboratórios: solo, água, nutrição vegetal, nutrição animal e alimentos. São Carlos: Embrapa Pecuária Sudoeste, 2005. p.145-199.

PACHECO, L.P.; BARBOSA, J.M.; LEANDRO, W.M.; MACHADO, P.L.O. de A.; ASSIS, R.L. de; MADARI, B.E.; PETTER, F.A. Produção e ciclagem de nutrientes por plantas de cobertura nas culturas de arroz de terras altas e soja. Revista Brasileira de Ciência do Solo, v.35, p.1787-1799, 2011a. DOI: 10.1590/S0100-06832011000500033.

PACHECO, L.P.; LEANDRO, W.M.; MACHADO, P.L.O. de A.; ASSIS, R.L. de; COBUCCI, T.; MADARI, B.E.; PETTER, F.A. Produção de fitomassa e acúmulo e liberação de nutrientes por plantas de cobertura na safrinha. Pesquisa Agropecuária Brasileira, v.46, p.17-25, 2011b. DOI: 10.1590/S0100-204X2011000100003.

PACHECO, L.P.; PIRES, F.R.; MONTEIRO, F.P.; PROCÓPIO, S.O.; ASSIS, R.L. de; CARMO, M.L.; PETTER, F.A. Desempenho de plantas de cobertura em sobressemeadura na cultura da soja. Pesquisa Agropecuária Brasileira, v.43, p.815-823, 2008. DOI: 10.1590/S0100-204X2008000700005.

PAUL, E.A.; CLARK, F.E. Soil microbiology and biochemistry. San Diego: Academic Press, 1989. 275p.

REIS, M.de S.; SOARES,A.A.; CORNELIO, V.M. de O.; SOARES, P.C. Desempenho de cultivares e linhagens de arroz de terras altas sob plantio direto e convencional. Ciência e Agrotecnologia, v.32, p.1435-1440, 2008. DOI: 10.1590/S1413-70542008000500012.

REIS, V.M.; REIS JUNIOR, F.B. dos; QUESADA, D.M.; OLIVEIRA, O.C.A. de; ALVES, B.J.R.; URQUIAGA, S.; BODDEY, R.M. Biological nitrogen fixation associated with 
tropical pasture grasses. Australian Journal of Plant Physiology, v.28, p.837-844, 2001. DOI: 10.1071/PP01079.

SANO, E.E.; ROSA, R.; BRITO, J.L.S.; FERREIRA, L.G. Mapeamento semidetalhado do uso da terra do Bioma Cerrado. Pesquisa Agropecuária Brasileira, v.43, p.153-156, 2008. DOI: 10.1590/S0100-204X2008000100020.

SANTOS, H.G. dos; JACOMINE, P.K.T.; ANJOS, L.H.C. dos; OLIVEIRA, V.A. de; OLIVEIRA, J.B. de; COELHO, M.R.; LUMBRERAS, J.F.; CUNHA, T.J.F. (Ed.). Sistema brasileiro de classificação de solos. 2.ed. Rio de janeiro: Embrapa Solos, 2006. $306 \mathrm{p}$.

SNEDECOR, G.W.; COCHRAN, W.G. Statistical methods. $8^{\text {th }}$ ed. Ames: Iowa State University, 1989. 503p.
SOUZA, L.S.; VELINI, E.D.; MARTINS, D.; ROSOLEM, C.A. Efeito alelopático de capim-braquiária (Brachiaria decumbens) sobre o crescimento inicial de sete espécies de plantas cultivadas. Planta Daninha, v.24, p.657-668, 2006. DOI: 10.1590/ S0100-83582006000400006.

TORRES, J.L.R.; PEREIRA, M.G.; FABIAN, A.J. Produção de fitomassa por plantas de cobertura e mineralização de seus resíduos em plantio direto. Pesquisa Agropecuária Brasileira, v.43, p.421-428, 2008. DOI: 10.1590/ S0100-204X2008000300018.

WIEDER, R.K.; LANG, G.E. A critique of the analytical methods used in examining decomposition data obtained from litter bags. Ecology, v.63, p.1636-1642, 1982. DOI: 10.2307/1940104.

Recebido em 3 de abril de 2013 e aprovado em 8 de agosto de 2013 